\title{
“Pillaring Effects" in Cross-Linked Cellulose Biopolymers: A Study of Structure and Properties
}

\author{
Inimfon A. Udoetok $\left(\mathbb{D},{ }^{1}\right.$ Lee D. Wilson ${ }^{D},{ }^{1}$ and John V. Headley ${ }^{2}$ \\ ${ }^{1}$ Department of Chemistry, 110 Science Place, University of Saskatchewan, Saskatoon, SK, Canada S7N 5C9 \\ ${ }^{2}$ Water Science and Technology Directorate, 11 Innovation Boulevard, Environment and Climate Change Canada, Saskatoon, SK, \\ Canada S7N $3 H 5$
}

Correspondence should be addressed to Lee D. Wilson; lee.wilson@usask.ca

Received 26 April 2018; Revised 5 July 2018; Accepted 16 July 2018; Published 23 August 2018

Academic Editor: Yiqi Yang

Copyright (C) 2018 Inimfon A. Udoetok et al. This is an open access article distributed under the Creative Commons Attribution License, which permits unrestricted use, distribution, and reproduction in any medium, provided the original work is properly cited.

Modified cellulose materials (CLE-4, CLE-1, and CLE-0.5) were prepared by cross-linking with epichlorohydrin (EP), where the products display variable structure, morphology, and thermal stability. Adsorptive probes such as nitrogen gas and phenolic dyes in aqueous solution reveal that cross-linked cellulose has greater accessible surface area (SA) than native cellulose. The results also reveal that the SA of cross-linked cellulose increased with greater EP content, except for CLE-0.5. The attenuation of SA for CLE-0.5 may relate to surface grafting onto cellulose beyond the stoichiometric cellulose and EP ratio since ca. $30 \%$ of the hydroxyl groups of cellulose are accessible for cross-linking reaction due to its tertiary fibril nature. Scanning electron microscopy (SEM) results reveal the variable surface roughness and fibre domains of cellulose due to cross-linking. X-ray diffraction (XRD) and ${ }^{13} \mathrm{C}$ NMR spectroscopy indicate that cellulose adopts a one-chain triclinic unit cell structure (P1 space group) with gauche-trans $(g t)$ and trans-gauche $(t g)$ conformations of the glucosyl linkages and hydroxymethyl groups. The structural characterization results reveal that cross-linking of cellulose occurs at the amorphous domains. By contrast, the crystalline domains are preserved according to similar features in the XRD, FTIR, and ${ }^{13} \mathrm{C}$ NMR spectra of cellulose and its cross-linked forms. This study contributes to an improved understanding of the role of cross-linking of native cellulose in its structure and functional properties. Cross-linked cellulose has variable surface functionality, structure, and textural properties that contribute significantly to their unique physicochemical properties over its native form.

\section{Introduction}

Cellulose is one of the most abundant and renewable biopolymers on earth $[1,2]$. It is environmentally benign, biodegradable, recyclable, and renewable. Notwithstanding the structural complexity and recalcitrant nature of cellulose, its relative abundance and low cost have drawn interest to its alternative and sustainable use as a raw material over petrochemical-based feedstocks [1-3]. While there are various strategies for the synthetic modification of cellulose, cross-linking is known to alter the physicochemical properties due to pillaring effects $[4,5]$. Previous studies have shown that the introduction of cross-links within a biopolymer network alters the textural, hydration, and mechanical properties, along with the chemical stability toward biodegradation [6-10]. The structure and physicochemical properties of cross-linked polymers related to adsorption (e.g., morphology, thermal stability, solvent swelling, crystallinity, and surface chemistry) differ compared with unmodified (native) polymers. The enhancement of such properties has led to diverse industrial and biomedical applications [11], aerospace and electronics [12], sorbents for wastewater treatment (decolorization and chelation of pollutants), or extraction of metals [13] and textile manufacturing [14].

The structure of native cellulose is complex and displays unique water adsorption and lipophilic surface area that relate to its complex fibril morphology and the variable accessibility of the hydrophilic groups. The unique hydrophilelipophile surface characteristics of cellulose are revealed by calorimetric results since its known hydration states are characterized by free and nonfreezing/freezable water. In the case of free water, it is categorized as unbound water in polymers; 
while nonfreezing bound water is strongly bound to the accessible hydroxyl groups, freezable bound water has weak interactions with the biopolymer chain. Free water undergoes similar freezing to normal bulk water (below $0^{\circ} \mathrm{C}$ according to the cooling rate) while freezable bound water solidifies well below the normal freezing point of bulk water.

Cross-linked cellulose (cf. Scheme 1) has been reported [6, 15-18], where complete cross-linking with epichlorohydrin (EP) results in a net loss of one hydroxyl group. In turn, cross-linking alters the hydrophile-lipophile balance of the biopolymer and its physicochemical properties. This is inferred due to changes in the surface functional groups and their accessibility due to structural modification [17]. As well, cross-linking modifies the textural properties (surface area and pore structure) of biopolymers due to pillaring effects [18] where the linkers are inferred to serve as bridges (pillars) between the biopolymer units (cf. Scheme 1). The textural properties of cellulose and its modified forms are anticipated to have variable thermodynamics and kinetics of hydration due to the role of pillaring effects on the biopolymer structure and properties. In an effort to obtain a greater understanding of the role of pillaring effects for cross-linked materials, a detailed structural characterization is needed since sparse studies exist for cellulose materials [19-21].

This study was motivated to address the above knowledge gaps through a systematic investigation of the structureproperty relationship concerning the role of pillaring effects and adsorption-based properties [22-24] for cellulose and its cross-linked forms. Herein, the morphology, structure, conformation, and thermal stability of cellulose materials was studied by a range of spectroscopic (FTIR, XRD, SEM, and solution/solid-state ${ }^{13} \mathrm{C}$ NMR) methods along with thermal analysis. This study highlights several contributions related to cellulose-modified materials: (i) the development of a greater understanding of semicrystalline/amorphous domains of cellulose and cross-linking and (ii) the use of a multi-instrumental study of cellulose and its cross-linked forms to develop an improved understanding of pillaring effects and adsorption-based properties. This study represents a first example that details the structural characterization of cellulose and its physicochemical properties (thermal stability and hydration) in relation to the role of pillaring effects. In turn, a greater understanding of the physicochemical properties of cellulose and its cross-linked forms will advance the science and technology of such materials. We envisage that such biopolymer materials can be synthetically engineered for specialized solid phase extraction (SPE) of steroids or lipids for analytical to biotechnology applications to address chemical separations in complex media such as urine to water/alcohol mixtures $[7,25]$.

\section{Material and Methods}

2.1. Materials. Cellulose (medium fibre from cotton linters), epichlorohydrin (EP), $\mathrm{HCl}, \mathrm{NaOH}$, potassium bromide (KBr), phenolphthalein (phth), p-nitrophenol (PNP), sodium bicarbonate, deuterated dimethyl sulfoxide (DMSO- $d_{6}$ ), and 1-butyl-3-methylimidazolium chloride $\left([\mathrm{C} 4 \mathrm{Mim}]^{+} \mathrm{Cl}^{-}\right)$ionic liquid (IL) was obtained from Sigma-Aldrich Canada Ltd.
(Oakville, ON). HPLC-grade acetone was obtained from Fisher Scientific (NJ, USA). All chemicals used were of ACS grade unless specified and were used as received without further purification.

2.2. Synthesis of Cross-Linked Cellulose. The synthesis of cross-linked cellulose was modified from a previous report [6]. In brief, cellulose ( $2 \mathrm{~g}$ ) was cross-linked upon dropwise addition over one minute of EP with heating and stirring in $16 \mathrm{~mL}$ of $2 \mathrm{M} \mathrm{NaOH}$ in a $100 \mathrm{~mL}$ round-bottom flask under argon gas at $80^{\circ} \mathrm{C}$ for $3 \mathrm{~h}$. Requisite volumes of $\mathrm{EP}(\rho=1.18$ $\mathrm{g} / \mathrm{mL}$ ) corresponding to different cellulose to cross-linker feed ratios (varied from low to high, 4 to 0.5 ) were used in Table 1 . The reaction was stirred for $12 \mathrm{~h}$ before neutralization with $1 \mathrm{M} \mathrm{HCl}$ solution. The product was separated from the supernatant by vacuum filtration and washed with several generous portions of cold Millipore water, followed by drying at ca. $50^{\circ} \mathrm{C}$. The dry product was exhaustively washed in a Soxhlet extractor with HPLC-grade acetone for $24 \mathrm{~h}$ followed by drying in a vacuum oven at $56^{\circ} \mathrm{C}$ for $12 \mathrm{~h}$. The material was ground in a mortar and pestle and isolated using a 40mesh sieve.

\subsection{Characterization of Cellulose Materials}

2.3.1. FTIR Studies. FTIR spectra were obtained using a BioRad FTS-40 spectrophotometer with powdered samples by mixing with pure spectroscopic grade $\mathrm{KBr}$ in a polymer/ $\mathrm{KBr}$ weight ratio of $1: 10$ followed by grinding in a small mortar and pestle. The diffuse reflectance infrared Fourier transform (DRIFT) spectra were obtained in reflectance mode at $295 \mathrm{~K}$ with a resolution of $4 \mathrm{~cm}^{-1}$ over the $400-$ $4000 \mathrm{~cm}^{-1}$ spectral range. 16 scans were recorded and corrected relative to a background of pure $\mathrm{KBr}$. Quantification of the spectral bands was carried out by integration of the FTIR signatures using OriginPro 2015 software.

\subsubsection{Thermogravimetric Analyses (TGA). Thermogravimet-} ric properties of the materials were measured using a Q50 (TA Instruments) operating with a heating rate of $5^{\circ} \mathrm{C} \cdot \mathrm{min}^{-1}$ up to $500^{\circ} \mathrm{C}$ with a nitrogen carrier gas. Thermograms were integrated using OriginPro 2015 software.

2.3.3. Elemental Analyses. Elemental microanalyses were obtained with a PerkinElmer $2400 \mathrm{CHN}$ Elemental Analyzer. The combustion oven temperature was set above $925^{\circ} \mathrm{C}$ while the reduction oven was held above $640^{\circ} \mathrm{C}$. The instrument was purged with a mixture of pure oxygen and helium gas. The calibration standard was acetanilide. Elemental analysis results of samples were obtained in duplicate with an estimated precision of $\pm 0.3 \%$. The degree of substitution and weight content (\%) of EP in the products was estimated from the $\mathrm{CHN}$ results.

2.3.4. X-Ray Diffraction (XRD) Studies. XRD spectra of the samples were obtained using a Panalytical Empyrean powder $\mathrm{X}$-ray diffractometer with monochromatic $\mathrm{Co}-\mathrm{K} \alpha 1$ radiation and an applied voltage $(40 \mathrm{kV})$ with a fixed current $(45 \mathrm{~mA})$. Samples were mounted in a horizontal configuration after evaporation of methanol films, and the XRD patterns were 


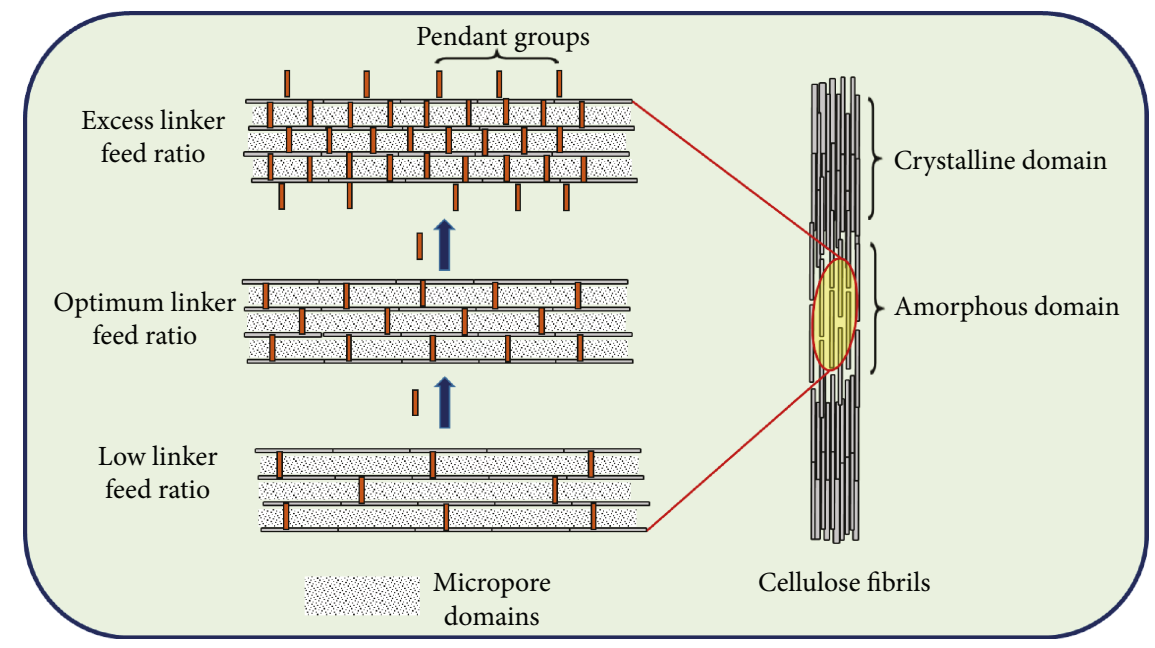

Scheme 1: Incremental cross-linking ("pillaring”) of the fibril structure of cellulose by variable cross-linking with epichlorohydrin.

TABLE 1: Synthetic ratios of cellulose and epichlorohydrin (EP) for cross-linked cellulose.

\begin{tabular}{lccc}
\hline Reaction conditions & CLE- $4^{*}$ & CLE-1 & CLE-0.5* \\
\hline Weight of EP (g) & $0.28^{* *}$ & $1.14^{* *}$ & $2.28^{* *}$ \\
Moles of EP & 0.00303 & 0.0123 & 0.0246 \\
Moles of cellulose & 0.0123 & 0.0123 & 0.0123 \\
Weight of product (g) & 1.40 & 1.54 & 1.74 \\
Mole ratio (cellulose: EP) & $4.05^{* * *}$ & $1.00^{* * *}$ & $0.50^{* * *}$ \\
\hline
\end{tabular}

${ }^{*}$ Numerical descriptors in the cross-linked polymer refer to the ratio of moles of cellulose monomer $\left(\mathrm{C}_{6} \mathrm{H}_{10} \mathrm{O}_{5}\right)_{n}$ to EP. ${ }^{* *}$ Calculated using a density value $1.18 \mathrm{~g} / \mathrm{mL}\left(25^{\circ} \mathrm{C}\right) .{ }^{* * *}$ Ratio of cellulose monomer $\left(\mathrm{C}_{6} \mathrm{H}_{10} \mathrm{O}_{5}\right)_{n}$ to EP.

measured in continuous mode over a $2 \theta$ range $\left(2 \theta=7-50^{\circ}\right)$ with a scan rate of $3.2^{\circ} \cdot \mathrm{min}^{-1}$. The crystallinity index $(\mathrm{CrI})$ was calculated from the intensity ratio of the crystalline peak $\left(I_{002}-I_{\mathrm{AM}}\right)$ and total intensity $\left(I_{002}\right)$. Unit cell parameters were obtained using Le Bail refinement fitting based on the unit cell parameters of cellulose $1 \alpha$, due to similarity between the diffraction patterns of cross-linked cellulose materials and simulated pattern of cellulose $1 \alpha$ [26].

2.3.5. Solid-State ${ }^{13} \mathrm{C}$ NMR Spectroscopy. ${ }^{13} \mathrm{C}$ solid NMR spectra were obtained with a wide-bore $(89 \mathrm{~mm})$ spectrometer operating at $8.6 \mathrm{~T}$ using an Oxford superconducting magnet system equipped with a $4 \mathrm{~mm}$ solid probe with cross polarization and magic angle spinning (CP-MAS) operating at 125.55 MHz. Acquisition parameters were controlled using an Avance DRX-360 console and workstation running TopSpin 1.3 (Bruker BioSpin Corp; Billerica, MA, USA), along with standard pulse programs in the TopSpin1.3 software. Samples were packed in $4 \mathrm{~mm}$ outer diameter zirconium oxide rotors capped with Teflon MAS rotor caps. Acquisition was carried out using MAS with a rotational speed of $5 \mathrm{kHz}$, $2 \mathrm{~s}$ recycle delay, and $750 \mu \mathrm{s}$ cross polarization time. The spectra were referenced externally to adamantane $(\delta=38.6$ $\mathrm{ppm}$ ) as an internal standard.
2.3.6. ${ }^{13} \mathrm{C}$ NMR Spectroscopy in Solution. ${ }^{13} \mathrm{C}$ NMR spectroscopy in solution was carried out on a Bruker TopSpin $3.2(5.0 \mathrm{~mm}$ PABBO probe) spectrometer operating at 125.55 MHz. All solution NMR spectra of the cellulose materials were obtained in an ionic liquid/DMSO- $d_{6}$ solvent. The samples were prepared by use of $1 \mathrm{~g}$ of $[\mathrm{C} 4 \mathrm{Mim}]^{+} \mathrm{Cl}^{-}$with heating and stirring at $363 \mathrm{~K}$ in a $3 \mathrm{~mL}$ vial for about 5 minutes. Then, $25 \mathrm{mg}$ of the cellulose sample was added and a clear solution was achieved after 20 min. DMSO- $d_{6}(80 \mu \mathrm{L})$ was added to the IL solution to serve as a deuterium field lock for the spectral acquisition. NMR spectra were acquired at $353 \mathrm{~K}$, where the chemical shifts $(\delta)$ of ${ }^{13} \mathrm{C}$ nuclei were measured relative to tetramethylsilane (TMS; $\delta=0.0 \mathrm{ppm}$ ) as the internal standard. The acquisition parameters were as follows: spectral width of $7560 \mathrm{~Hz}$, acquisition time of $1.48 \mathrm{~s}$, recycle delay of $4 \mathrm{~s}$, and a file size of $22 \mathrm{k}$ data points.

2.3.7. Scanning Electron Microscopy (SEM). The surface morphology of cellulose and its modified forms were studied using scanning electron microscopy (SEM; Model JSM6010 , JEOL/EO). The samples were sputter-coated with gold, and the images were collected under the following instrument conditions: accelerating voltage $10 \mathrm{kV}, 9 \mathrm{~mm}$ working distance (WD), magnification 3000x, and spot size 50. The dimensions of the fibre domains were estimated by use of Image J analysis software.

2.3.8. Nitrogen Adsorption/Desorption Isotherms. The surface area and pore structure properties were determined by nitrogen adsorption using a Micromeritics ASAP 2020 (Norcross, GA) system. Briefly, approximately $1.0 \mathrm{~g}$ sample was degassed at the following conditions: an evacuation rate of $5 \mathrm{mmHg} \cdot \mathrm{s}^{-1}$ in the sample chamber to a stable outgas rate of $<10 \mathrm{mmHg} \cdot \mathrm{min}^{-1}$. The degassing temperature for the samples was set at ca. $100^{\circ} \mathrm{C}$ for $72 \mathrm{~h}$. The instrumental parameters were calibrated using alumina (Micromeritics). The BET surface area was calculated from the adsorption isotherm profile using $0.162 \mathrm{~nm}^{2}$ as the surface area for gaseous molecular nitrogen $[27,28]$. The micropore SA was obtained using a $t$-plot (de Boer method) [29]. The Barret-Joyner-Halenda 
$(\mathrm{BJH})$ method was used to estimate the pore volume and pore diameter from the adsorption isotherm profile.

2.3.9. Dye Adsorption Studies. Dye adsorption studies of $p$-nitrophenol and phenolphthalein were used to determine the accessible surface area (SA) and surface accessibility of the hydroxyl groups of cellulose and its cross-linked forms. The accessible SA $\left(\mathrm{m}^{2} / \mathrm{g}\right)$ was estimated from the adsorption of PNP using (1). $Q_{m}$ is the monolayer adsorption capacity of the adsorbent-dye system at equilibrium $(\mathrm{mol} / \mathrm{g})$, obtained according to (2), $N$ is Avogadro's number (6.02214x $\left.10^{23} \mathrm{~mol}^{-1}\right), \sigma$ is the cross-sectional molecular area of the dye adsorbate $\left(\mathrm{m}^{2}\right)$, and $Y$ is the coverage factor $(Y=1$ for PNP) $[30,31]$. The coverage factor is determined according to the number of adsorbed layers of dye species at the surface of a solid adsorbent. The molecular area $(\sigma)$ is variable, where it is $52.5 \AA^{2}$ for PNP adsorbed in a coplanar orientation and $25.0 \AA^{2}$ for an orthogonal arrangement relative to a planar surface [27].

$$
\begin{aligned}
\mathrm{SA} & =\frac{Q_{\mathrm{m}} \times N \times \sigma}{Y}, \\
Q_{e} & =\frac{\left(C_{o}-C_{e}\right) \times V}{m} .
\end{aligned}
$$

Similarly, the accessibility of the hydroxyl groups of the materials was estimated by the decolorization of phenolphthalein (phth) at pH10.5 upon adsorption [32]. A $50 \mathrm{mM}$ stock solution of phth in ethanol $(66 \mu \mathrm{L})$ was diluted in $100 \mathrm{~mL}$ of sodium bicarbonate buffer ( $\mathrm{pH} 10.5)$ to yield a $33 \mu \mathrm{M}$ aqueous solution. A $7 \mathrm{~mL}$ aqueous solution containing phth $(33 \mu \mathrm{M})$ was added to vials containing incremental weights of the cellulose sample. The mixtures were shaken for $24 \mathrm{~h}$, centrifuged (Precision Micro-Semi Micro Centricone, Precision Scientific Co.) at $1550 \mathrm{rpm}$, and the absorbance of the supernatant was measured using a double-beam spectrophotometer (Varian Cary 100) at $295 \pm 0.5 \mathrm{~K}$ to monitor the absorbance $\left(\lambda_{\max }=552 \mathrm{~nm}\right)$. All measurements were carried out in triplicate.

\section{Results and Discussion}

Previous studies of cross-linked cellulose polymers have been reported in the open literature [19-21], but there is a limited understanding of how cross-linking (pillaring) affects the physicochemical properties of such systems. To investigate the role of pillaring effects in cellulose, a multi-instrumental approach was used to evaluate the relationship between structure and physicochemical properties of cross-linked cellulose. To this end, several methods were used that include gas/dye adsorption, TGA, microscopy, and spectroscopy (SEM, UV-vis, FTIR, and NMR) to address this goal. The structure and physicochemical properties of cross-linked cellulose (CLE-X; X $=4,1$, and 0.5 ) were studied where materials with greater EP content are denoted by a smaller $\mathrm{X}$ indices (cf. Table 1).

3.1. FTIR Spectroscopy Results. The characterization of functional groups for insoluble cellulose materials in the solid state was achieved using diffuse reflectance infrared Fourier transform (DRIFT) spectroscopy. DRIFT spectral signatures were assigned to chemical bonds or functional groups, [33] (cf. Table S1 in the Supporting Information (SI)) for cellulose and its cross-linked forms. The salient spectral features in Table S1 include a broad band attributed to intermolecular bonded OH groups (cf. Figure 1(a)) ( 3000$\left.3600 \mathrm{~cm}^{-1}\right), \mathrm{C}-\mathrm{H}$ stretching $\left(\sim 2800-3000 \mathrm{~cm}^{-1}\right), \mathrm{O}-\mathrm{H}$ and $\mathrm{C}-\mathrm{H}$ bending $\left(\sim 1400-1300 \mathrm{~cm}^{-1}\right)$, and $\mathrm{C}-\mathrm{O}-\mathrm{H}$ and $\mathrm{C}-\mathrm{O}-\mathrm{C}$ asymmetric stretching $\left(\sim 1000-1200 \mathrm{~cm}^{-1}\right)$. The spectral signatures of cellulose and its cross-linked forms are highly overlapped. The band intensities $(\mathrm{C}-\mathrm{H}$ stretching, $\mathrm{C}-\mathrm{H}$ bending, and $\mathrm{C}-\mathrm{O}-\mathrm{H}$ and $\mathrm{C}-\mathrm{O}-\mathrm{C}$ asymmetric stretching) increase and become sharper as the linker content of the cellulose material increases, with the exception of CLE-0.5. The IR results provide support that the hydroxyl group of cellulose undergo cross-linking with the epoxide ring of EP, as described in detail elsewhere [34]. The increase in intensity and greater sharpness of these bands can be ascribed to pillaring effects of the cellulose fibrils. The pillaring effects result in a net decrease of one $\mathrm{OH}$ group per EP that undergoes cross-linking. The foregoing is supported by a previous study on cross-linked chitosan materials [5].

Quantitative analysis of these bands (cf. Figure 1(b)) provides additional supporting evidence that amorphization of the macromolecular structure of cellulose occurs as the EP content increases. The variable FTIR band intensity $\left(1427 \mathrm{~cm}^{-1}\right.$ and $\left.899 \mathrm{~cm}^{-1}\right)$ indicates that the crystallinity index $(\mathrm{CrI})$ of these materials shows parallel trends to the XRD and CP-MAS NMR results (cf. Figure 2(a) and Table S5 in SI) along with other related studies [35-37]. The amorphous domains of cellulose influences its hydration properties, as reported in a sorption calorimetry study of microcrystalline cellulose and milled cellulose [38]. Herein, it can be inferred that cross-linking of cellulose with EP alters the hydrogen bonding network of the biopolymer through pillaring effects, according to the reduced intensity of ${ }^{13} \mathrm{C}$ solid NMR spectral signatures of the amorphous cellulose domains. In the case of ${ }^{13} \mathrm{C}$ solid NMR spectra, the spectral lines for the D-glucose units of the cross-linked cellulose become sharper with increased EP content. The effect relates to greater motional dynamics of the cross-linked framework versus cellulose due to greater crystallinity and extensive hydrogen bonding of the native biopolymer network [39].

The relative similarity between the IR spectral signatures of native cellulose and its cross-linked forms indicates that the basic structural units and the crystalline domains are preserved, in agreement with parallel observations for crosslinked $\beta$-cyclodextrin reported elsewhere [40]. The attenuation of IR bands for the cross-linked cellulose are consistent with the net loss of one -OH group for each cross-link formed. In cases where excess EP undergoes cross-linking, as for the CLE-0.5 biopolymer, potential side reactions between EP and nonreacted pendant epoxy groups occur (cf. Scheme 1). This may contribute to secondary effects due to grafting versus cross-linking in the IR spectra [41]. The spectral signatures at about $1037-1200 \mathrm{~cm}^{-1}$ (C-O stretching and bending) and $2800-3000 \mathrm{~cm}^{-1}(\mathrm{C}-\mathrm{H}$ stretching vibrations) provide supporting evidence along with the 


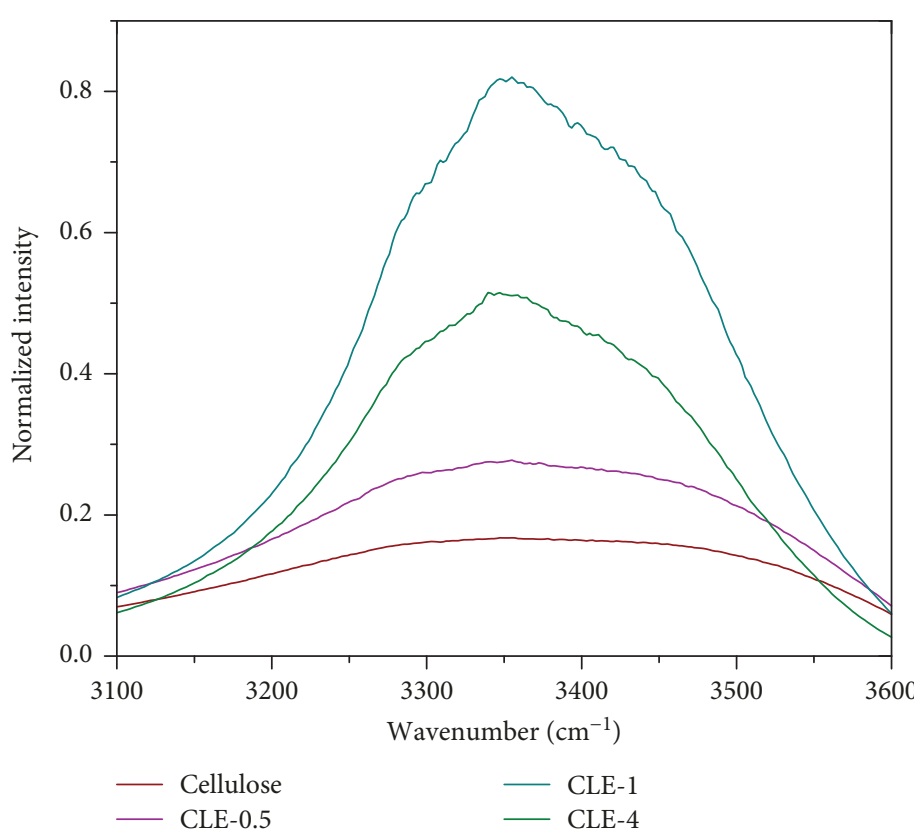

(a)

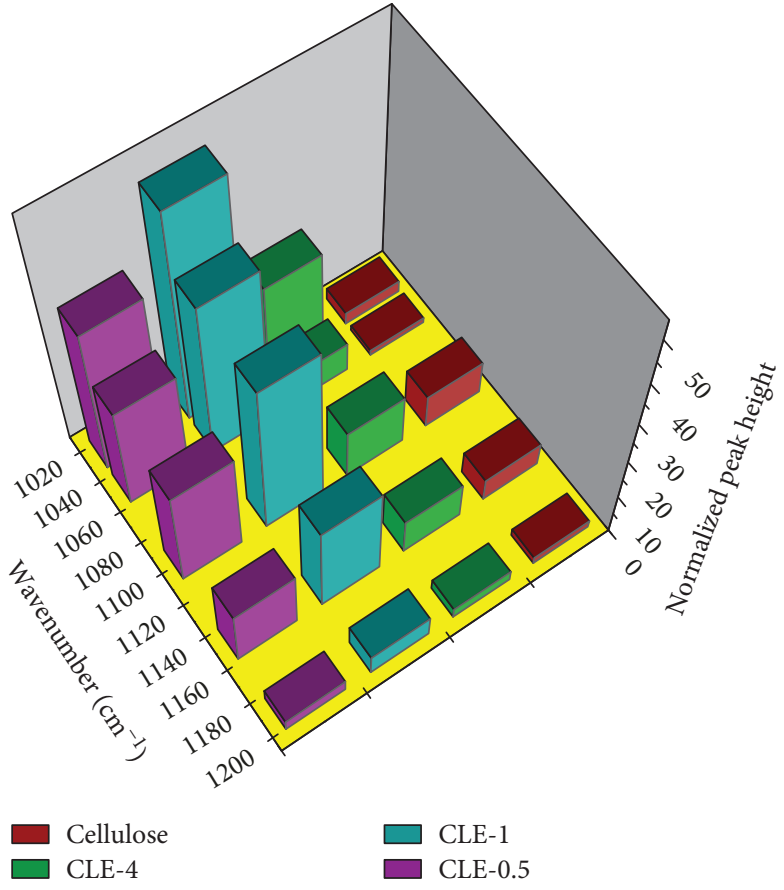

(b)

FIGURE 1: FTIR spectral results for cellulose and its cross-linked polymers: (a) -OH spectral region and (b) C-O peak areas.

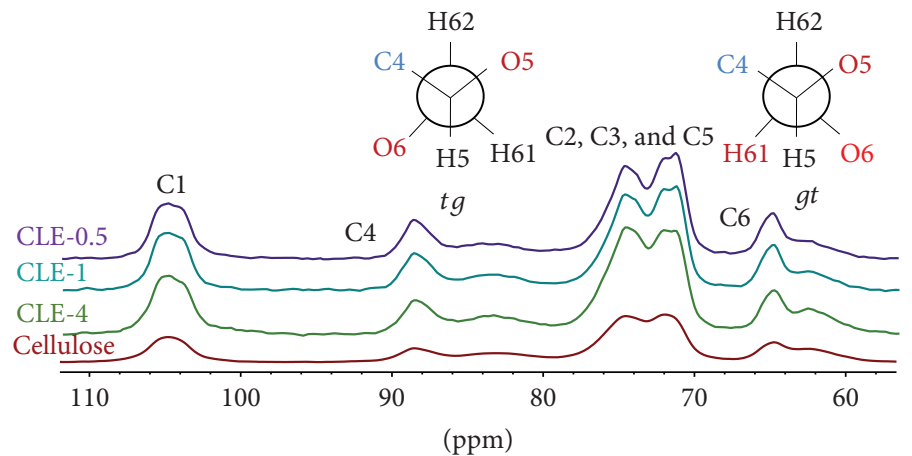

(a)

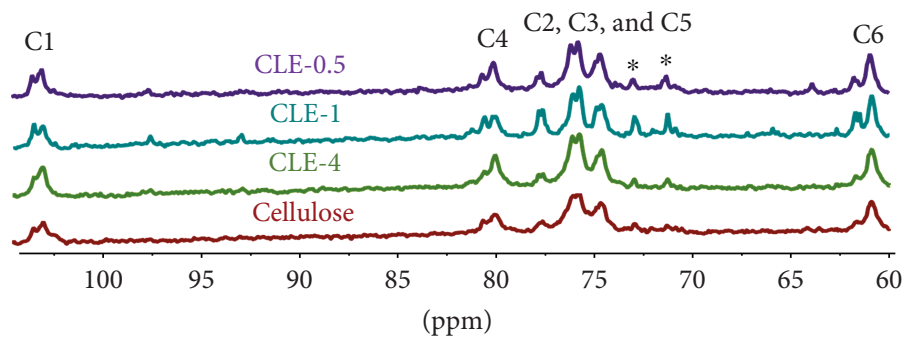

(b)

FIGURE 2: ${ }^{13} \mathrm{C}$ NMR spectra of cellulose and its cross-linked forms: (a) solid ${ }^{13} \mathrm{C}$ CP-MAS NMR spectra at $295 \mathrm{~K}$ and (b) solution NMR spectra in a IL-DMSO- $d_{6}$ solution system at $353 \mathrm{~K}$ where the asterisk $\left(^{*}\right)$ denotes signatures due to the EP linker unit.

presence of unique ${ }^{13} \mathrm{C}$ NMR lines between 70 and $74 \mathrm{ppm}$ (cf. Figure 2) for the cross-linked reaction products. The variation of the C6 signatures for the spectra in solution of the cross-linked cellulose strongly support that bonding occurs at the primary hydroxyl sites (C6-OH) [35-37]. FTIR studies [35-37] indicate that the IR spectral signatures at about 1037, 1057,1200 , and $1335 \mathrm{~cm}^{-1}$ relate to C-O stretching (C6 and/ or $\mathrm{C} 3$ ), $\mathrm{C}-\mathrm{O}-\mathrm{H}$ in-plane bending at $\mathrm{C} 6$, and in-plane bending 
at C2 or C3. An increase in the IR signal intensities of the bands at $2800-3000 \mathrm{~cm}^{-1}$ confirm the introduction of C-H groups from EP [41].

3.2. Thermal Gravimetric Analysis (TGA) Results. Crosslinked materials may possess modified thermal stability, as observed by use of thermal analysis methods [42, 43]. TGA profiles provide a relative assessment of the thermal stability since the weight loss profiles versus temperature indicate that thermal decomposition occurs, especially for structurally related materials $[40,44,45]$. The TGA results shown in Table S2 (SI) support that the native and cross-linked cellulose display thermal decomposition events between 200 and $400^{\circ} \mathrm{C}$. The thermal event for pristine cellulose is near $334^{\circ} \mathrm{C}$, while the cross-linked cellulose has variable temperature stability, as follows: CLE-4 ( 325.4 and $\left.359.1^{\circ} \mathrm{C}\right)$, CLE-1 $\left(\sim 322.6\right.$ and $\left.362.4^{\circ} \mathrm{C}\right)$, and CLE-0.5 $\left(\sim 310.1\right.$ and $\left.341.3^{\circ} \mathrm{C}\right)$.

The TGA results indicate that cross-linking of cellulose results in elevated decomposition temperatures, as compared to pristine cellulose. Shifts in the thermogram profiles provide support that cross-linking and surface grafting of EP alter the thermal stability $[6,18]$, in accordance with minor changes in the degree of cellulose crystallinity (vide infra). In Table S2, thermal events at $359.1^{\circ} \mathrm{C}, 362.4^{\circ} \mathrm{C}$, and $341.3^{\circ} \mathrm{C}$ relate to the decomposition of the cellulose-EP framework, whereas the decomposition of the EP component occurs at $325.4^{\circ} \mathrm{C}$ (CLE-4), $332.6^{\circ} \mathrm{C}$ (CLE-1), and $310.1^{\circ} \mathrm{C}$ (CLE-0.5). The variable thermal stability relates to changes in the heat capacity due to chemical cross-linking and changes in the textural properties (SA and pore structure) of cellulose. It may also be related to the role of surface grafting that contribute changes in the structure and morphology of cellulose (cf. Scheme 1). In general, greater thermal stability occurs as the cross-linker content increases, in agreement with other cross-linked polysaccharides $[6,18]$. An exception is noted for CLE-0.5 which has a stoichiometric excess of crosslinker relative to the equivalent number of available hydroxyl groups of cellulose. As noted above in Section 3.1 and Scheme 1, the formation of an EP-based oligomer or a surface grafted form of cellulose provides an account of the observed effects noted for CLE-0.5 (cf. Scheme S1 in SI). The formation of an EP oligomer agrees with the lower decomposition temperature of CLE-0.5 and corresponds to a thermal event observed for an EP-based homopolymer [46].

3.3. Elemental Analysis. Table S3 (SI) lists the results for the elemental analyses (CHO) of cellulose and its cross-linked forms, along with the related EP content. The results for EP (Table S3) are based on its formula weight after accounting for loss of $\mathrm{HCl}$ to enable comparison with the other cellulose materials. An increase in the C (\%) content occurs at increased cross-linking, in agreement with other studies for related materials $[47,48]$. In Table S3, the identity of the products varies according to the degree of substitution (CLE-4: 0.32, CLE-1: 0.33, and CLE-0.5: 0.39) and EP content: CLE-4: 9.91 wt.\%, CLE-1: 10.3 wt.\%, and CLE-0.5: 11.9 wt.\%. These results are consistent with the trends in elemental analysis and provide further support that crosslinking occurs between cellulose and EP for CLE-4 and
CLE-1. By contrast, cross-linking and surface grafting may occur for CLE-0.5.

3.4. X-Ray Diffraction (XRD). Structural changes for cellulose and its cross-linked forms were studied by XRD. The XRD results (Figure 3) of cellulose and its cross-linked forms are shown along with a sample of cellulose that was heattreated with $2 \mathrm{M} \mathrm{NaOH}$ for $3 \mathrm{~h}$. The XRD patterns display similar features with the following Miller indices, $\sim 16^{\circ}$ (101), $\sim 19^{\circ}$ (10i), $24^{\circ}$ (021), $\sim 26^{\circ}$ (002), and $\sim 40^{\circ}(040)$. These signatures are characteristic of cellulose I [49] and also concur with FTIR spectral results. Similar diffraction patterns are noted for each material in Figure 3 that parallel the FTIR results in Table S1, indicating that the basic structural units and crystalline domains of cellulose are well preserved. The refined unit cell parameters in Table S4 (SI) were calculated on the basis of known unit cell dimensions of cellulose $\mathrm{I} \alpha(a=6.717, b=5.962, c=10.400$, and $\alpha=$ $118.08, \beta=114.80$, and $\gamma=80.37)$ which vary slightly from reported values for $\mathrm{I} \alpha[26,50]$. This data supports a onechain triclinic unit cell structure (P1 space group) with glucosyl linkages and hydroxymethyl groups in the gauchetrans $(g t)$ and trans-gauche $(t g)$ conformations with dihedral angles of $180^{\circ}$ and $-60^{\circ}$, respectively [50]. The XRD spectra of the treated cellulose had a reduced 002 peak with a separation between 101 and $10 \mathrm{i}$ relative to cellulose and its cross-linked forms. This effect may relate to the greater accessibility of the amorphous domains of cellulose upon treatment with $\mathrm{NaOH}$, in agreement with previous reports $[37,51]$. These results are consistent with ${ }^{13} \mathrm{C}$ CP-MAS NMR spectral results, where no significant changes to the crystalline nature of cellulose are noted with greater cross-linking, in agreement with the CrI index reported herein (cf. Table S5; 70\%, CLE-4: 71.9\%, CLE-1: 70.2\%, and CLE-0.5: 73.9\%), along with a similar study [52].

3.5. Solid- and Solution-State ${ }^{13} \mathrm{C} N M R$ Spectroscopy. ${ }^{13} \mathrm{C}$ NMR spectroscopy is a valuable structural tool for the study of interactions of soluble and poorly soluble carbonaceous materials, especially for structurally complex materials with short- and long-range order similar to that of semicrystalline cellulose [40]. NMR studies carried out in the solid state and in solution provide complementary insight on the molecular structure, interactions, geometry, and dynamics of cellulose since the ${ }^{13} \mathrm{C}$ NMR spectral signature reveals information on its local environment and presence of short-range order/ disorder within the biopolymer network. ${ }^{13} \mathrm{C}$ NMR spectra obtained in solution yield sharper lines for polymers due to averaging of anisotropic interactions by fast isotropic molecular tumbling to produce well-defined spectral features. Figure 2 illustrates the respective ${ }^{13} \mathrm{C}$ solid CP-MAS and solution-based NMR spectra for cellulose and its crosslinked forms.

In Figures 2(a) and 2(b), the ${ }^{13} \mathrm{C}$ NMR spectra in the solid state and in solution reveal that the resonance lines of cellulose and its cross-linked forms reside over a well-defined spectral region (62-105 ppm), in agreement with other reports on cellulose and related polysaccharides [53-55]. The ${ }^{13} \mathrm{C} N M R$ spectra of cellulose in the solid state and in solution reveal 


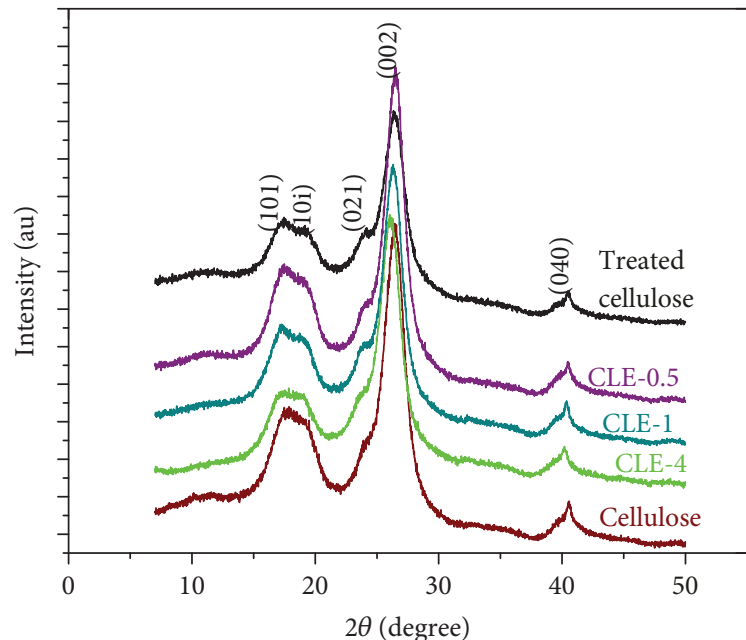

FIGURE 3: XRD patterns of cellulose and its cross-linked materials.

spectral features for C6 ( 61.1 ppm), C2 ( 74.5 ppm), C3 $(\sim 75.6 \mathrm{ppm}), \mathrm{C} 5(\sim 77.4 \mathrm{ppm}), \mathrm{C} 4(\sim 80.2 \mathrm{ppm})$, and $\mathrm{C} 1$ $(\sim 105 \mathrm{ppm})$, in good agreement with other NMR studies $[54,55]$. The ${ }^{13} \mathrm{C}$ NMR spectral lines for cross-linked cellulose materials show a slight shift versus native cellulose that indicates changes to the local chemical environment of $\mathrm{C} 2$-, C3-, and C6-OH groups upon cross-linking. The appearance of new resonance lines from the cross-linker domains confirms the covalent linkages between cellulose and EP. There is further evidence of cross-linking by the variable thermal events in the TGA profiles, intensity change of ${ }^{13} \mathrm{C}$ solid NMR spectra due to structure modification of the amorphous domains, and the FTIR bands at $\sim 1037-1200 \mathrm{~cm}^{-1}$ that appear upon cross-linking of cellulose. Related NMR studies for polymers cross-linked with EP reveal new ${ }^{13} \mathrm{C}$ NMR signatures at 69 to $73 \mathrm{ppm}$, in agreement with the NMR results reported herein. The ${ }^{13} \mathrm{C}$ NMR spectral signatures of modified cellulose bear similar structural features to the polymorphic form of native cellulose (type I) $[55,56]$ that concur with XRD results in Figure 3 . The ${ }^{13} \mathrm{C}$ NMR spectral results are further supported by a shift of the IR band at $1099 \mathrm{~cm}^{-1}$ assigned to the native polymorphic form (cellulose I). Evidence of changes in the fine structure of the cellulose backbone is also seen in the solution ${ }^{13} \mathrm{C}$ NMR spectra due to the isotropic conditions of the IL solvent system (Figure 2(b)). The trends are assigned to pillaring effects of cellulose due to changes in the motional dynamics of the biopolymer network in the solid NMR spectrum (Figure 2(a)). While the FTIR and SEM results do not show large variation with the level of cross-linking, evidence of cross-linking and pillaring effects is noted for cellulose from the NMR spectral results in Figure 2. The ${ }^{13} \mathrm{C}$ NMR signatures (Figure 2(a)) of cellulose (80 to $92 \mathrm{ppm}$ ) provide evidence of the crystalline and amorphous biopolymer domains [55, 57-59], along with other ${ }^{13} \mathrm{C}$ NMR signatures $(\delta=60-65 \mathrm{ppm})$. The sharper ${ }^{13} \mathrm{C}$ NMR bands at $\sim 92 \mathrm{ppm}$ and $\sim 65 \mathrm{ppm}$ relate to a crystalline domain of cellulose while bands at $\sim 80 \mathrm{ppm}$ and $\sim 60 \mathrm{ppm}$ are due to amorphous domains. A comparison of the ${ }^{13} \mathrm{C}$ CP-MAS NMR spectra of microcrystalline and amorphous cellulose reveals the absence of C4 ( 88 ppm) and C6
( $\sim 65 \mathrm{ppm})$ signatures for amorphous cellulose [55], and this may relate to differences in the dynamics and the crosspolarization transfer efficiency due to the morphology of these different materials. The chemical shift values for the C6 nuclei agree with the $g t$ - and $t g$-preferred conformation of hydroxymethyl groups, where the dihedral angles are $180^{\circ}$ and $-60^{\circ}$, respectively, in agreement with other reports and XRD results $[60,61]$. Herein, a comparison of the NMR spectra of cellulose and its cross-linked forms (Figure 2(a)) shows attenuated NMR line intensity $(\delta=80$ to $84 \mathrm{ppm}$ and $62 \mathrm{ppm}$ ) attributed to ${ }^{13} \mathrm{C}$ NMR spectral signatures for amorphous cellulose. The NMR results provide supporting evidence that structural changes occur upon cross-linking that influence biopolymer solvation that differ uniquely with native cellulose. The similar crystallinity index estimated by the XRD results for native cellulose and its cross-linked forms suggests that the amorphous domains undergo a cross-linking process while the crystalline domains appear largely unaffected.

3.6. Scanning Electron Microscopy (SEM). SEM provides evidence of the changes in morphology and surface character of polymers due to cross-linking, as shown by the SEM micrographs for cellulose and its cross-linked forms (Figures 4(a)4(d)). The micrographs reveal variable surface morphology and fibre structure of cellulose when compared with crosslinked cellulose. The SEM results for cellulose (Figure 4(a)) show evidence of fibre bundle assemblies with a slightly roughened surface appearance and attenuated pore structure. By contrast, the SEM results for cross-linked cellulose (Figures 4(b)-4(d)) show greater variation in the surface roughness upon cross-linking. Evidence of fibre bundle disintegration is noted by the mesoporous polymer surface in Figures 4(b)-4(d), as compared with unmodified cellulose. The loss of fibre structure is further evidenced by the formation of small individual particulates with variable shape that appear as semiordered and closely packed structures. A variable fibril structure was observed as the EP content increased, where an exception was noted for CLE-0.5, in agreement with the trend in fibre size. The largest identified fibre in the SEM micrographs (cellulose: $14.5 \pm 0.2 \mu \mathrm{m}$, CLE-4: $11.3 \pm 0.2 \mu \mathrm{m}$, CLE-1: $9.6 \pm 0.1 \mu \mathrm{m}$, and CLE-0.5: $14.4 \pm$ $0.2 \mu \mathrm{m}$ ) along with the variable thermal stability (cf. Table S2 in SI) provides support for the change in molecular structure. The SEM image of CLE-0.5 reveals small fibril strands which appear entangled, as evidenced by the formation or exposure of new fibril bundles in accordance with the effects of excess EP and surface grafting of cellulose, as described in Sections 3.1 to 3.5.

The entanglement may relate to self-reaction via crosslinking and/or EP surface grafted cellulose species due to the excess EP cross-linker used in the synthesis, in good agreement with the lower thermal decomposition temperature of CLE- 0.5 from TGA studies (cf. Table S2 in SI). A comparison of the SEM images of cellulose and CLE-0.5 reveals that such materials have large fibril bundles where individual strands show slight size variation. Cellulose and CLE-0.5 have larger fibrils $(14.4-14.5 \pm 0.2 \mu \mathrm{m})$ that provide further evidence of cellulose surface grafting, especially for CLE- 0.5 
due to the use of an excess linker for its synthesis (cf. Figure 4).

3.7. Dye-Based and Nitrogen Adsorption Surface Area Estimates. Dye-based methods for use in solid-solution and gas adsorption isotherms for solid-gas systems provide complementary characterization of textural (surface area (SA) and pore structure) properties of materials from isotherm studies. [62]. However, it should be noted that differences exist for SA estimates from solid-gas isotherms versus solid-solution systems using dye-based methods. The differences may relate to solvent swelling which has been previously reported for starch and cellulose biopolymers [62, 63]. Estimates of SA for cross-linked polymers from adsorption isotherm studies were obtained using PNP in aqueous media and nitrogen gas as the adsorbate probes (Figure 5). The inset in Figure 5 shows that CLE- 1 had the largest SA among the cellulose materials and was attributed to the optimum stoichiometric synthetic ratio used for the reaction since the surface accessibility of the $-\mathrm{OH}$ groups of unmodified cellulose is about $30 \%$. Among the biopolymers, native cellulose had the lowest SA based on the dye adsorption method (cf. Table 2 and inset of Figure 5), in agreement with complementary results obtained from FTIR, SEM, solution/solidstate ${ }^{13} \mathrm{C}$ NMR spectroscopy, and phth decolorization. On the basis of reactions with surface accessible -OH groups at the amorphous domains of cellulose, EP cross-linking with cellulose yields materials with variable morphology and textural properties (cf. Figures 4 and 5 in [39]), in agreement with studies on EP cross-linked cyclodextrin materials [40].

Gas adsorption/desorption isotherms provide a standard approach for the characterization of textural properties of porous materials $[28,62]$. The isotherm for CLE-1 with nitrogen is shown in Figure 5. This system corresponds to a type II isotherm according to the International Union of Pure and Applied Chemistry (IUPAC) adsorbent classification system. The saturation of the monolayer occurs at a lower relative pressure $\left(p / p^{\circ}\right) \approx 0.2$ while greater adsorption occurs at $p / p>0.8$, in agreement with results for other cross-linked polysaccharides [5]. The isotherm displays low gas uptake up to a relative pressure $\left(p / p^{\circ}\right)$ below 0.8 , while greater adsorption occurs for $p / p>0.8$ due to adsorption at the grain boundaries of the material [6]. The BET SA estimate for CLE-1 is relatively low $\left(1.91 \mathrm{~m}^{2} \cdot \mathrm{g}^{-1}\right)$, where the average pore width is about $10.1 \mathrm{~nm}$ which is similar to unmodified cellulose $\left(\mathrm{SA}=0.957 \mathrm{~m}^{2} \cdot \mathrm{g}^{-1}\right)$. Similar SA values for cellulose and its cross-linked forms relate to the number (ca. 30\%) of accessible -OH groups of cellulose that do not allow for complete pillaring of the cellulose fibrils. This interpretation is supported by evidence of crystalline domains and surface grafting in CLE-0.5, where a stoichiometric excess of the EP cross-linker was used. A similar solvent swelling (\%) for CLE-0.5 and C-EP sonication is listed in Table 2. In the case of C-EP, greater surface grafting was reported [39] for sonication-assisted synthesis conditions that further affirm that cross-linking and surface grafting occur for CLE-0.5. The apparent SA obtained by the dye-based method and nitrogen adsorption reveals differences in the estimated values by each of the two methods which are in accordance

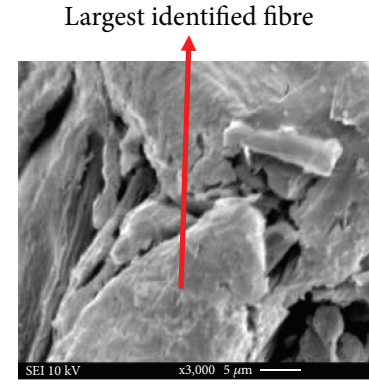

(a)

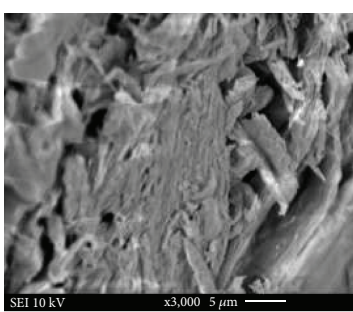

(c)

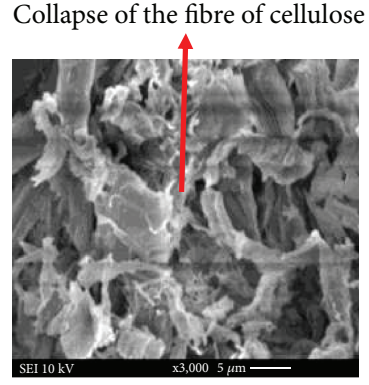

(b)

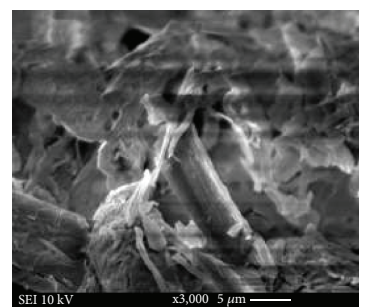

(d)
Figure 4: SEM micrographs of (a) cellulose, (b) CLE-4, (c) CLE-1, and (d) CLE-0.5 at $295 \mathrm{~K}$.

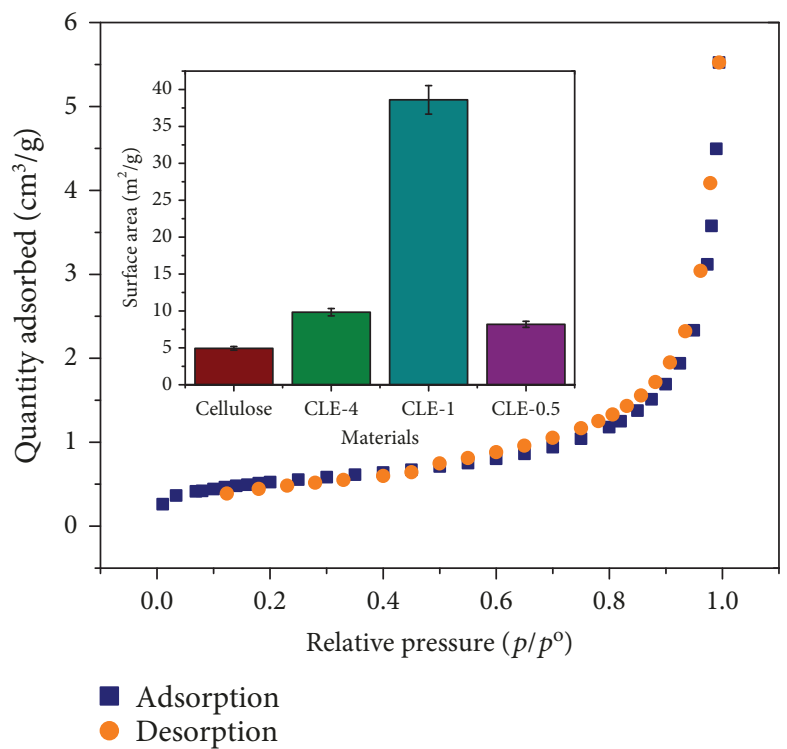

FIGURE 5: Nitrogen adsorption/desorption isotherms of cellulose materials, where the inset provides SA estimates using the dyebased method with PNP.

with solvent swelling effects in water, as outlined herein. Variable SA was reported [64] for never-dried and air-dried commercial softwood cellulose fibres, where it was noted that the mode of drying of cellulose led to morphological changes due to collapse of its biopolymer network structure upon loss of solvent [65].

3.8. Phenolphthalein (phth) Decolorization. Physicochemical properties such as SA and pore structure contribute 
TABLE 2: Effect of cross-linking on the physicochemical properties of biomaterials.

\begin{tabular}{|c|c|c|c|c|c|c|}
\hline Material & Precursor & $Q_{\mathrm{m}}(\mathrm{mg} / \mathrm{g})$ & Dye-based SA $\left(\mathrm{m}^{2} / \mathrm{g}\right)$ & $\mathrm{N}_{2}$-based SA $\left(\mathrm{m}^{2} / \mathrm{g}\right)$ & Water swelling (\%) & Reference \\
\hline Native & Cellulose & $2.17^{*}$ & $4.93^{*}$ & 0.957 & 161 & {$[18,39]$} \\
\hline Cellulose & & $0.23^{\dagger}$ & & & & This work \\
\hline CLE- 0.5 & Cellulose & $4.33^{*}$ & $9.83^{*}$ & NA & 215 & {$[18]$} \\
\hline CLE-2 & Cellulose & $17.0^{*}$ & $38.6^{*}$ & NA & 205 & {$[18]$} \\
\hline CLE-1 & Cellulose & NA & $\mathrm{NA}$ & 1.91 & NA & This work \\
\hline CLE-4 & Cellulose & 3.60 & 8.19 & NA & 297 & {$[18]$} \\
\hline C-EP (heating) & Cellulose & $1.85^{\dagger}$ & NA & 1.18 & 260 & {$[39]$} \\
\hline C-EP (sonication) & Cellulose & $0.82^{\dagger}$ & NA & 0.871 & 280 & [39] \\
\hline CE-1 & Cellulose & $72.8^{*}$ & NA & NA & 244 & [6] \\
\hline CE-2 & Cellulose & $45.2^{*}$ & NA & $\mathrm{NA}$ & 205 & {$[6]$} \\
\hline CE-3 & Cellulose & $24.6^{*}$ & NA & NA & 161 & {$[6]$} \\
\hline CPL-1 & Chitosan & $114^{*}$ & $124^{*}$ & NA & NA & {$[33]$} \\
\hline CPL-2 & Chitosan & $43.0^{*}$ & $46.7^{*}$ & NA & NA & [33] \\
\hline CPL-3 & Chitosan & $29.2^{*}$ & $31.6^{*}$ & NA & NA & {$[33]$} \\
\hline
\end{tabular}

* denote values obtained with $p$-nitrophenol (PNP) with $Q_{\mathrm{m}}$ values originally reported in mmol/g. $\dagger$ denote values obtained with 2 -naphthoxy acetic acid (NAA). NA: not available.

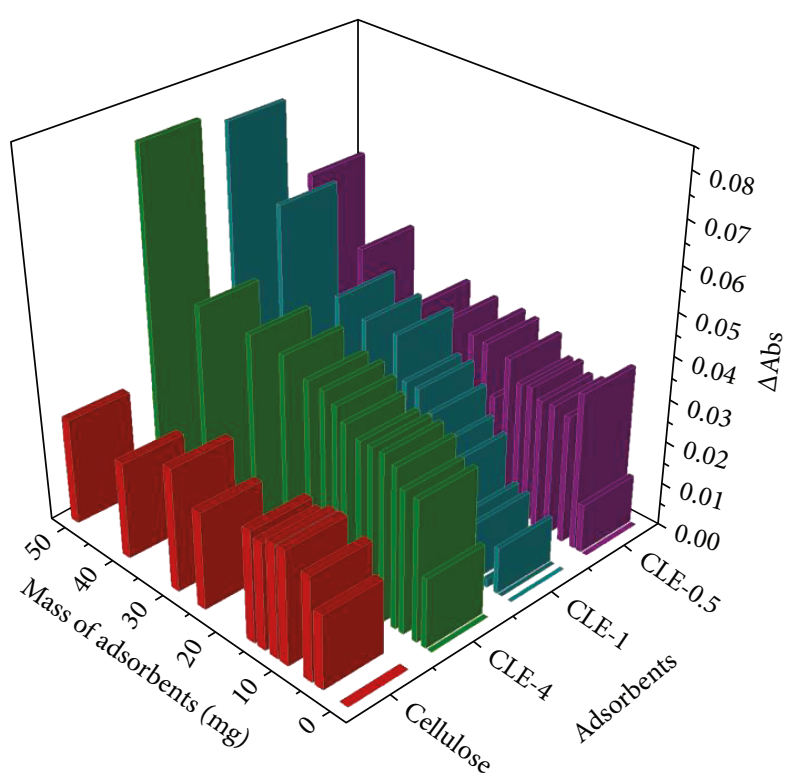

FIGURE 6: Phenolphthalein decolorization in aqueous solution with variable amounts of cellulose and cross-linked polymers at $295 \mathrm{~K}$ and $\mathrm{pH} 10.5$.

significantly to the sorption properties of amorphous and nontemplated porous materials $[32,66]$. Cross-linking and other surface modification $[17,42,43,67]$ alter the textural properties of polysaccharide materials as revealed by dye adsorption methods. Dye decolorization results for phth with cellulose and its cross-linked forms are shown in Figure 6. The trends reveal that pristine cellulose had the lowest decolorization effect on phth, while greater decolorization effects $(\Delta \mathrm{Abs})$ occur for cross-linked cellulose with increased surface accessibility of $-\mathrm{OH}$ groups, in agreement with results for such biopolymers [68]. Thus, the relationship between the level of cross-linking and surface accessibility of the $\mathrm{OH}$ groups is supported by the ${ }^{13} \mathrm{C}$ NMR line intensity variation of EP signatures for cross-linked cellulose (cf. Figure 2) and the IR spectral intensity of the $-\mathrm{OH}$ groups (cf. Figure 1(a)). According to a previous study [69], decolorization of phth was related to hydrogen bonding interactions that result in $\mathrm{pK}_{\mathrm{a}}$ shifts of the bound dye due to complex formation with the biopolymer $-\mathrm{OH}$ groups [68]. The $-\mathrm{OH}$ group surface accessibility of cellulose and steric effects for its cross-linked forms correlate with $\Delta \mathrm{Abs}$, in agreement with a study of cyclodextrin polymers [70]. The hydroxyl groups of cellulose have low surface accessibility (ca. 30\%) due to its fibril morphology that results from extensive hydrogen bonding of the biopolymer network. The role of crosslinking is hypothesized to result in pillaring of the fibril structure that changes the textural properties of cross-linked chitosan relative to the unmodified biopolymer [5]. Crosslinking is asserted to introduce defects into the hydrogen bond network that enhance the surface accessibility of the hydroxyl groups due to pillaring effects (cf. Scheme 1), as revealed by more effective dye decolorization. Cross-linking of cellulose with EP results in a net loss of one hydroxyl group of cellulose for each cross-link formed (cf. Scheme S1 in SI). At elevated levels of cross-linking, the $-\mathrm{OH}$ group surface accessibility of cellulose may reveal steric effects $[32,68]$, in agreement with changes in morphology noted in the SEM results (Figure 4). In general, the dye adsorption results for cellulose and its cross-linked forms reveal enhanced adsorption properties due to the greater binding site accessibility by solvent and dye adsorbates.

3.9. Comparison with Other Cross-Linked Cellulose Polymers. A comparison of the cross-linked cellulose polymers in this work with other studies is provided in Table 3. Many polymers were prepared in homogenous media, whereas the 
TABLE 3: Summary of studies for cross-linked cellulose polymers.

\begin{tabular}{|c|c|c|c|}
\hline Reactants & Reaction media & Structural characterization & Ref. \\
\hline Cellulose, EP & $\begin{array}{c}\text { Homogeneous } \\
\text { (urea/NaOH solution) }\end{array}$ & TGA, AFM, and UV-vis spectroscopy & {$[71]$} \\
\hline Cellulose, $\mathrm{EP}$, and $\mathrm{NH}_{4} \mathrm{OH}$ & Heterogeneous & FTIR & {$[72]$} \\
\hline Nanocellulose, polyamideamine-EP (PAE) & Homogeneous & SEM and $\mathrm{Hg}$ porosimetry & [73] \\
\hline Cellulose, EP, $\mathrm{NH}_{4} \mathrm{OH}$, and $\mathrm{NaIO}_{2}$ & Heterogeneous & XRD, TGA, and FTIR & {$[74]$} \\
\hline CMC, EP & Homogeneous & SEM and FTIR & {$[75]$} \\
\hline Bulk cellulose and EP & Heterogeneous & $\begin{array}{c}\text { FTIR, SEM, XRD, TGA, solid/solution }{ }^{13} \mathrm{C} \text { NMR, } \\
\text { dye decolorization, } \mathrm{N}_{2} \text { adsorption, and } \\
\text { dye-based SA estimates }\end{array}$ & This work \\
\hline
\end{tabular}

polymers in this study were modified under heterogeneous conditions due to the limited solubility of cellulose in aqueous media. In many cases, the structural properties of the polymers in Table 3 were not extensively characterized, as compared with the complementary methods reported herein that included adsorption isotherms, TGA, SEM, and spectroscopy (UV-vis, FTIR, and NMR).

\section{Conclusions}

Cellulose was structurally modified by cross-linking with EP at variable mole ratios. Structural characterization was carried out in solution and the solid state by various complementary methods to reveal that cross-linking occurs at the amorphous versus crystalline domain of cellulose. The claim that the cross-linking of cellulose occurred at the amorphous domains is affirmed by similar features in the XRD patterns and FTIR and ${ }^{13} \mathrm{C}$ NMR spectra of the materials. Gas adsorption with nitrogen and dye adsorption (PNP and phth) in aqueous media along with SEM results reveal that crosslinked cellulose has a unique structure and morphology that differs relative to that of pristine cellulose. Cross-linking of cellulose in the amorphous domains led to pillaring effects of the biopolymer network (cf. Scheme 1). Evidence of the pillaring of cellulose fibrils was further affirmed by the improved (up to $\approx 8$-fold greater; Figure 6) adsorption properties of cross-linked versus native cellulose. Pillaring effects contribute to greater surface accessibility of polar functional groups $(-\mathrm{OH})$ and active sites that favour adsorption and hydration properties of the cross-linked biopolymer. A key outcome of this study concerns the role of the amorphous domains of cellulose that undergo cross-linking since the crystalline domains are structurally preserved and do not appear to undergo any appreciable cross-linking reaction. This study will contribute favourably to the valorization and utilization of native cellulose since its synthetic utility and recalcitrant nature is governed by the relative crystallinity (amorphous versus crystalline domains) of the biopolymer. By contrast, the physicochemical properties of cellulose can be tuned via cross-linking of the amorphous cellulose domains in a controlled fashion, where such materials may have utility as advanced SPE materials in biotechnology for lipid fractionation to environmental remediation of petrochemicals in aquatic environments and chemical separations $[6,11,76]$.

\section{Data Availability}

The data used to support the findings of this study are available from the corresponding author upon request.

\section{Conflicts of Interest}

The authors declare that they have no conflicts of interest.

\section{Supplementary Materials}

Scheme S1: cross-linking reaction between two cellulose repeat units and epichlorohydrin in aqueous solution. Table S1: FTIR band assignments for cellulose and various crosslinked forms. Table S2: TGA results for cellulose and its cross-linked materials. Table S3: elemental analysis results of cellulose and its cross-linked forms. Table S4: unit cell parameters of cellulose materials and cross-linked forms. Table S5: crystallinity index of cellulose and the crosslinked polymers. Table S6: selected physicochemical properties of dyes. (Supplementary Materials)

\section{References}

[1] X. Qiu and S. Hu, "'Smart" materials based on cellulose: a review of the preparations, properties, and applications," Materials, vol. 6, no. 3, pp. 738-781, 2013.

[2] A. Yamazawa, T. Iikura, A. Shino, Y. Date, and J. Kikuchi, "Solid-, solution-, and gas-state NMR monitoring of ${ }^{13} \mathrm{C}$-cellulose degradation in an anaerobic microbial ecosystem," Molecules, vol. 18, no. 8, pp. 9021-9033, 2013.

[3] T. Mekonnen, P. Mussone, H. Khalil, and D. Bressler, "Progress in bio-based plastics and plasticizing modifications," Journal of Materials Chemistry A, vol. 1, no. 43, pp. 1337913398, 2013.

[4] T. Oyama, "Cross-linked polymer synthesis," Encyclopedia of Polymeric Nanomaterials, pp. 496-505, 2015.

[5] M. H. Mohamed, I. A. Udoetok, L. D. Wilson, and J. V. Headley, "Fractionation of carboxylate anions from aqueous solution using chitosan cross-linked sorbent materials," RSC Advances, vol. 5, no. 100, pp. 82065-82077, 2015.

[6] L. Dehabadi and L. D. Wilson, "Polysaccharide-based materials and their adsorption properties in aqueous solution," Carbohydrate Polymers, vol. 113, pp. 471-479, 2014.

[7] L. Dehabadi and L. D. Wilson, "Nuclear magnetic resonance investigation of the fractionation of water-ethanol mixtures 
with cellulose and Its cross-linked biopolymer forms," Energy \& Fuels, vol. 29, no. 10, pp. 6512-6521, 2015.

[8] S. Rimdusit, K. Somsaeng, P. Kewsuwan, C. Jubsilp, and S. Tiptipakorn, "Comparison of gamma radiation crosslinking and chemical crosslinking on properties of methylcellulose hydrogel," Engineering Journal, vol. 16, no. 4, pp. 15-28, 2012.

[9] V. K. Thakur and M. K. Thakur, "Processing and characterization of natural cellulose fibers/thermoset polymer composites," Carbohydrate Polymers, vol. 109, pp. 102-117, 2014.

[10] Z. Yue-Hong, Z. Wu-Quan, G. Zhen-Hua, and G. Ji-You, "Effects of crosslinking on the mechanical properties and biodegradability of soybean protein-based composites," Journal of Applied Polymer Science, vol. 132, no. 5, 2015.

[11] N. Reddy, R. Reddy, and Q. Jiang, "Crosslinking biopolymers for biomedical applications," Trends in Biotechnology, vol. 33, no. 6, pp. 362-369, 2015.

[12] K. Vanherck, G. Koeckelberghs, and I. F. J. Vankelecom, "Crosslinking polyimides for membrane applications: a review," Progress in Polymer Science, vol. 38, no. 6, pp. 874896, 2013.

[13] A. S. Ayoub and S. S. H. Rizvi, "An overview on the technology of cross-linking of starch for nonfood applications," Journal of Plastic Film \& Sheeting, vol. 25, no. 1, pp. 25-45, 2009.

[14] S. Thaseen, "Durable press treatments to cotton, viscose, bamboo and tencel fabrics," International Journal of Research in Engineering and Technology, vol. 3, no. 8, pp. 32-35, 2014.

[15] Y. Li, H. Xiao, M. Chen, Z. Song, and Y. Zhao, "Absorbents based on maleic anhydride-modified cellulose fibers/diatomite for dye removal," Journal of Materials Science, vol. 49, no. 19, pp. 6696-6704, 2014.

[16] R. J. Moon, A. Martini, J. Nairn, J. Simonsen, and J. Youngblood, "Cellulose nanomaterials review: structure, properties and nanocomposites," Chemical Society Reviews, vol. 40, no. 7, pp. 3941-3994, 2011.

[17] I. Udoetok, L. Wilson, and J. Headley, "Quaternized cellulose hydrogels as sorbent materials and pickering emulsion stabilizing agents," Materials, vol. 9, no. 8, pp. 645-660, 2016.

[18] I. A. Udoetok, R. M. Dimmick, L. D. Wilson, and J. V. Headley, "Adsorption properties of cross-linked celluloseepichlorohydrin polymers in aqueous solution," Carbohydrate Polymers, vol. 136, pp. 329-340, 2016.

[19] Y.-X. Bai and Y.-F. Li, "Preparation and characterization of crosslinked porous cellulose beads," Carbohydrate Polymers, vol. 64, no. 3, pp. 402-407, 2006.

[20] J. A. Seo, J. C. Kim, J. K. Koh, S. H. Ahn, and J. H. Kim, "Preparation and characterization of crosslinked cellulose/sulfosuccinic acid membranes as proton conducting electrolytes," Ionics, vol. 15, no. 5, pp. 555-560, 2009.

[21] M. J. Peña, S. T. Tuomivaara, B. R. Urbanowicz, M. A. O'Neill, and W.S. York, "Methods for structural characterization of the products of cellulose- and xyloglucan-hydrolyzing enzymes," Methods in Enzymology, vol. 510, pp. 121-139, 2012.

[22] T. Heinze and T. Liebert, "Unconventional methods in cellulose functionalization," Progress in Polymer Science, vol. 26, no. 9, pp. 1689-1762, 2001.

[23] M. Ioelovich, "Cellulose as a nanostructured polymer: a short review," BioResources, vol. 3, no. 4, pp. 1403-1418, 2008.

[24] F. H. A. Rodrigues, C. Spagnol, A. G. B. Pereira et al., "Superabsorbent hydrogel composites with a focus on hydrogels containing nanofibers or nanowhiskers of cellulose and chitin," Journal of Applied Polymer Science, vol. 131, no. 2, 2014.
[25] N. A. Manaf, B. Saad, M. H. Mohamed, L. D. Wilson, and A. A. Latiff, "Cyclodextrin based polymer sorbents for micro-solid phase extraction followed by liquid chromatography tandem mass spectrometry in determination of endogenous steroids," Journal of Chromatography A, vol. 1543, pp. 23-33, 2018.

[26] A. D. French, "Idealized powder diffraction patterns for cellulose polymorphs," Cellulose, vol. 21, no. 2, pp. 885-896, 2014.

[27] T. Allen, Particle Size Measurement: Volume 2: Surface Area and Pore Size Determination, Springer, London, UK, 1997.

[28] K. Sing, "The use of nitrogen adsorption for the characterisation of porous materials," Colloids and Surfaces A: Physicochemical and Engineering Aspects, vol. 187-188, pp. 3-9, 2001.

[29] J. C. P. Broekhoff and J. H. de Boer, "Studies on pore systems in catalysts: XI. Pore distribution calculations from the adsorption branch of a nitrogen adsorption isotherm in the case of "ink-bottle" type pores," Journal of Catalysis, vol. 10, no. 2, pp. 153-165, 1968.

[30] C. H. Giles, T. H. MacEwan, S. N. Nakhwa, and D. Smith, "786. Studies in adsorption. Part XI. A system of classification of solution adsorption isotherms, and its use in diagnosis of adsorption mechanisms and in measurement of specific surface areas of solids," Journal of the Chemical Society (Resumed), pp. 3973-3993, 1960.

[31] M. M. Lynam, J. E. Kilduff, and W. J. Weber Jr, “Adsorption of p-nitrophenol from dilute aqueous solution: an experiment in physical chemistry with an environmental application," Journal of Chemical Education, vol. 72, no. 1, p. 80, 1995.

[32] M. H. Mohamed, L. D. Wilson, and J. V. Headley, "Estimation of the surface accessible inclusion sites of $\beta$-cyclodextrin based copolymer materials," Carbohydrate Polymers, vol. 80, no. 1, pp. 186-196, 2010.

[33] D. Y. Pratt, L. D. Wilson, and J. A. Kozinski, "Preparation and sorption studies of glutaraldehyde cross-linked chitosan copolymers," Journal of Colloid and Interface Science, vol. 395, pp. 205-211, 2013.

[34] S. Eyley and W. Thielemans, "Surface modification of cellulose nanocrystals,” Nanoscale, vol. 6, no. 14, pp. 7764-7779, 2014.

[35] C. P. Azubuike and A. O. Okhamafe, "Physicochemical, spectroscopic and thermal properties of microcrystalline cellulose derived from corn cobs," International Journal of Recycling of Organic Waste in Agriculture, vol. 1, no. 1, pp. 9-16, 2012.

[36] X. Colom and F. Carrillo, "Crystallinity changes in lyocell and viscose-type fibres by caustic treatment," European Polymer Journal, vol. 38, no. 11, pp. 2225-2230, 2002.

[37] S. Y. Oh, D. I. Yoo, Y. Shin et al., "Crystalline structure analysis of cellulose treated with sodium hydroxide and carbon dioxide by means of X-ray diffraction and FTIR spectroscopy," Carbohydrate Research, vol. 340, no. 15, pp. 2376-2391, 2005.

[38] V. Kocherbitov, S. Ulvenlund, M. Kober, K. Jarring, and T. Arnebrant, "Hydration of microcrystalline cellulose and milled cellulose studied by sorption calorimetry," The Journal of Physical Chemistry B, vol. 112, no. 12, pp. 3728-3734, 2008.

[39] I. A. Udoetok, L. D. Wilson, and J. V. Headley, "Ultra-sonication assisted cross-linking of cellulose polymers," Ultrasonics Sonochemistry, vol. 42, pp. 567-576, 2018.

[40] D. Y. Pratt, L. D. Wilson, J. A. Kozinski, and A. M. Mohart, "Preparation and sorption studies of $\beta$-cyclodextrin/epichlorohydrin copolymers," Journal of Applied Polymer Science, vol. 116, no. 5, pp. 2982-2989, 2010. 
[41] X. Hou, J. Yang, J. Tang, X. Chen, X. Wang, and K. Yao, “Preparation and characterization of crosslinked polysucrose microspheres," Reactive and Functional Polymers, vol. 66, no. 12, pp. 1711-1717, 2006.

[42] A. H. Karoyo and L. D. Wilson, "Nano-sized cyclodextrinbased molecularly imprinted polymer adsorbents for perfluorinated compounds-a mini-review," Nanomaterials, vol. 5, no. 2, pp. 981-1003, 2015.

[43] M. H. Mohamed, L. D. Wilson, and J. V. Headley, "Tuning the physicochemical properties of $\beta$-cyclodextrin based polyurethanes via cross-linking conditions," Microporous and Mesoporous Materials, vol. 214, pp. 23-31, 2015.

[44] M. H. Mohamed, L. D. Wilson, and J. V. Headley, "Design and characterization of novel $\beta$-cyclodextrin based copolymer materials," Carbohydrate Research, vol. 346, no. 2, pp. 219229, 2011.

[45] J. Singh, N. S. Mishra, Uma, S. Banerjee, and Y. C. Sharma, "Comparative studies of physical characteristics of raw and modified sawdust for their use as adsorbents for removal of acid dye," Bioresources, vol. 6, no. 3, pp. 2732-2743, 2011.

[46] Y. Ren, G. Wu, X. Zhao, X. Liu, and F. Liu, "Effect of poly(epichlorohydrin) on the thermal and mechanical properties of poly(vinyl chloride)," Journal of Applied Polymer Science, vol. 118, no. 6, pp. 3416-3424, 2010.

[47] G. Ma, B. Qian, J. Yang, C. Hu, and J. Nie, "Synthesis and properties of photosensitive chitosan derivatives(1)," International Journal of Biological Macromolecules, vol. 46, no. 5, pp. 558-561, 2010.

[48] L. Poon, S. Younus, and L. D. Wilson, "Adsorption study of an organo-arsenical with chitosan-based sorbents," Journal of Colloid and Interface Science, vol. 420, pp. 136-144, 2014.

[49] J. Bian, F. Peng, X. P. Peng, P. Peng, F. Xu, and R. C. Sun, "Acetic acid enhanced purification of crude cellulose from sugarcane bagasse: structural and morphological characterization," BioResources, vol. 7, no. 4, 2012.

[50] Y. Nishiyama, J. Sugiyama, H. Chanzy, and P. Langan, "Crystal structure and hydrogen bonding system in cellulose I $\alpha$ from synchrotron X-ray and neutron fiber diffraction," Journal of the American Chemical Society, vol. 125, no. 47, pp. 1430014306, 2003.

[51] I. P. Samayam, B. L. Hanson, P. Langan, and C. A. Schall, "Ionic-liquid induced changes in cellulose structure associated with enhanced biomass hydrolysis," Biomacromolecules, vol. 12, no. 8, pp. 3091-3098, 2011.

[52] D. Ishimura, Y. Morimoto, and H. Saito, "Influences of chemical modifications on the mechanical strength of cellulose beads," Cellulose, vol. 5, no. 2, pp. 135-151, 1998.

[53] F. Aloulou, S. Boufi, and J. Labidi, "Modified cellulose fibres for adsorption of organic compound in aqueous solution," Separation and Purification Technology, vol. 52, no. 2, pp. 332-342, 2006.

[54] J. S. Moulthrop, R. P. Swatloski, G. Moyna, and R. D. Rogers, "High-resolution ${ }^{13} \mathrm{C}$ NMR studies of cellulose and cellulose oligomers in ionic liquid solutions," Chemical Communications, no. 12, pp. 1557-1559, 2005.

[55] C. D. Tran, S. Duri, A. Delneri, and M. Franko, "Chitosancellulose composite materials: preparation, characterization and application for removal of microcystin," Journal of Hazardous Materials, vol. 252-253, pp. 355-366, 2013.
[56] R. H. Newman and T. C. Davidson, "Molecular conformations at the cellulose-water interface," Cellulose, vol. 11, no. 1, pp. 23-32, 2004.

[57] P. T. Larsson, U. Westermark, and T. Iversen, "Determination of the cellulose I $\alpha$ allomorph content in a tunicate cellulose by CP/MAS ${ }^{13}$ C-NMR spectroscopy," Carbohydrate Research, vol. 278, no. 2, pp. 339-343, 1995.

[58] P. T. Larsson, K. Wickholm, and T. Iversen, "A CP/MAS ${ }^{13} \mathrm{C}$ NMR investigation of molecular ordering in celluloses," Carbohydrate Research, vol. 302, no. 1-2, pp. 19-25, 1997.

[59] Y. Sun, L. Lin, H. B. Deng et al., "Structural changes of bamboo cellulose in formic acid," BioResources, vol. 3, no. 2, pp. 297$315,2008$.

[60] F. Horii, A. Hirai, and R. Kitamaru, "Solid-state ${ }^{13} \mathrm{C}-\mathrm{NMR}$ study of conformations of oligosaccharides and cellulose," Polymer Bulletin, vol. 10, no. 7-8, pp. 357-361, 1983.

[61] Y. Yoneda, K. Mereiter, C. Jaeger et al., "van der Waals versus hydrogen-bonding forces in a crystalline analog of cellotetraose: cyclohexyl 4'-O-Cyclohexyl $\beta$-D-cellobioside cyclohexane solvate," Journal of the American Chemical Society, vol. 130, no. 49, pp. 16678-16690, 2008.

[62] L. D. Wilson, M. H. Mohamed, and J. V. Headley, "Surface area and pore structure properties of urethane-based copolymers containing $\beta$-cyclodextrin," Journal of Colloid and Interface Science, vol. 357, no. 1, pp. 215-222, 2011.

[63] L. Dehabadi, F. Fathieh, L. D. Wilson, R. W. Evitts, and C. J. Simonson, "Study of dehumidification and regeneration in a starch coated energy wheel," ACS Sustainable Chemistry \& Engineering, vol. 5, no. 1, pp. 221-231, 2016.

[64] M. Kimura, Z.-D. Qi, H. Fukuzumi, S. Kuga, and A. Isogai, "Mesoporous structures in never-dried softwood cellulose fibers investigated by nitrogen adsorption," Cellulose, vol. 21, no. 5, pp. 3193-3201, 2014.

[65] X. Jie, Y. Cao, J.-J. Qin, J. Liu, and Q. Yuan, "Influence of drying method on morphology and properties of asymmetric cellulose hollow fiber membrane," Journal of Membrane Science, vol. 246, no. 2, pp. 157-165, 2005.

[66] G. Crini, "Recent developments in polysaccharide-based materials used as adsorbents in wastewater treatment," Progress in Polymer Science, vol. 30, no. 1, pp. 38-70, 2005.

[67] I. A. Udoetok, L. D. Wilson, and J. V. Headley, "Self-assembled and cross-linked animal and plant-based polysaccharides: chitosan-cellulose composites and their anion uptake properties," ACS Applied Materials \& Interfaces, vol. 8, no. 48, pp. 3319733209, 2016.

[68] M. H. Mohamed, L. D. Wilson, J. V. Headley, and K. M. Peru, "Thermodynamic properties of inclusion complexes between $\beta$-cyclodextrin and naphthenic acid fraction components," Energy \& Fuels, vol. 29, no. 6, pp. 3591-3600, 2015.

[69] M. Bertau and G. Jörg, "Saccharides as efficacious solubilisers for highly lipophilic compounds in aqueous media," Bioorganic \& Medicinal Chemistry, vol. 12, no. 11, pp. 2973-2983, 2004.

[70] M. H. Mohamed, L. D. Wilson, D. Y. Pratt, R. Guo, C. Wu, and J. V. Headley, "Evaluation of the accessible inclusion sites in copolymer materials containing $\beta$-cyclodextrin," Carbohydrate Polymers, vol. 87, no. 2, pp. 1241-1248, 2012.

[71] B. Guo, W. Chen, and L. Yan, "Preparation of flexible, highly transparent, cross-linked cellulose thin film with high mechanical strength and low coefficient of thermal expansion," ACS Sustainable Chemistry \& Engineering, vol. 1, no. 11, pp. 1474-1479, 2013. 
[72] S. Saxena, S. Garg, and A. K. Jana, "Synthesis of cellulose based polymers for sorption of azo dyes from aqueous solution," Journal of Environmental Research \& Development, vol. 6, no. 3, 2012.

[73] Z. He, X. Zhang, and W. Batchelor, "Cellulose nanofibre aerogel filter with tuneable pore structure for oil/water separation and recovery," RSC Advances, vol. 6, no. 26, pp. 2143521438, 2016.

[74] S. Kumari, D. Mankotia, and G. S. Chauhan, "Crosslinked cellulose dialdehyde for Congo red removal from its aqueous solutions," Journal of Environmental Chemical Engineering, vol. 4, no. 1, pp. 1126-1136, 2016.

[75] W. Wei, S. Kim, M.-H. Song, J. K. Bediako, and Y.-S. Yun, "Carboxymethyl cellulose fiber as a fast binding and biodegradable adsorbent of heavy metals," Journal of the Taiwan Institute of Chemical Engineers, vol. 57, pp. 104-110, 2015.

[76] M. A. Hubbe, K. R. Beck, W. G. O'Neal, and Y. C. Sharma, "Cellulosic substrates for removal of pollutants from aqueous systems: a review. 2. Dyes,” Bioresources, vol. 7, no. 2, 2012. 


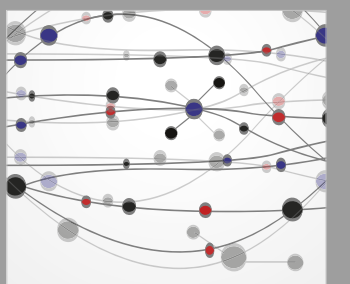

The Scientific World Journal
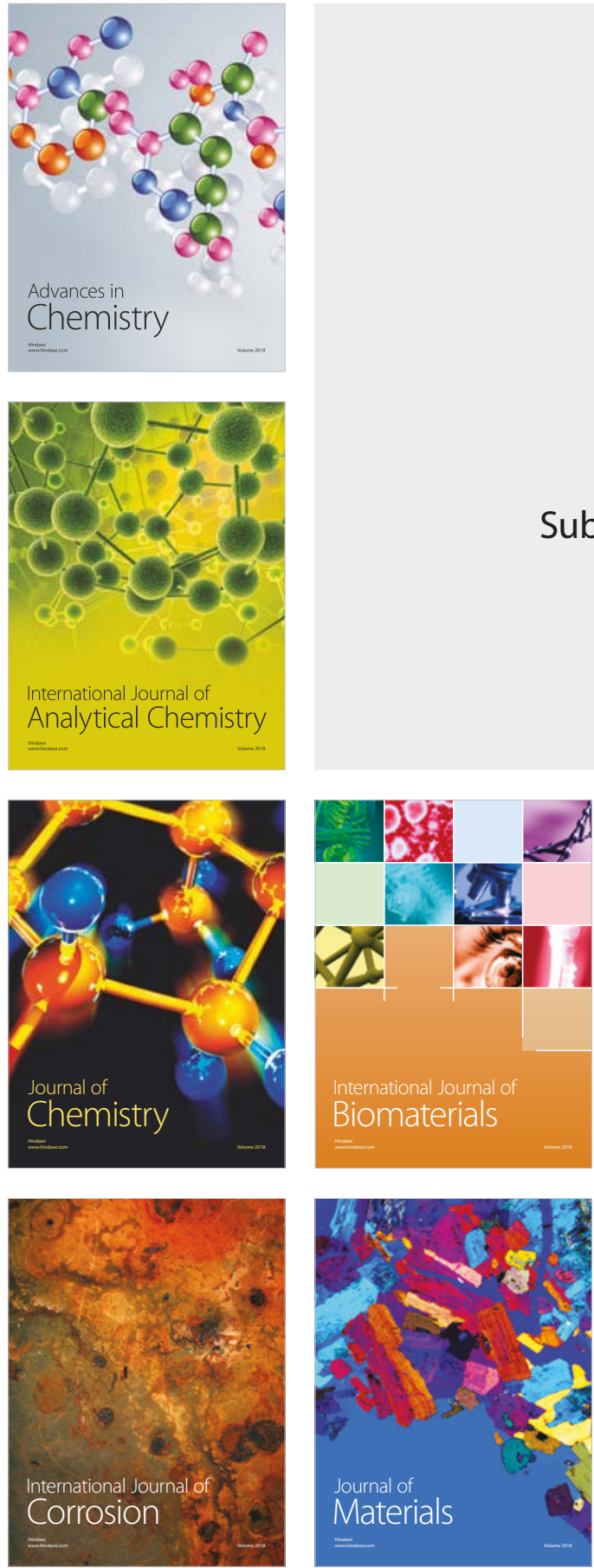

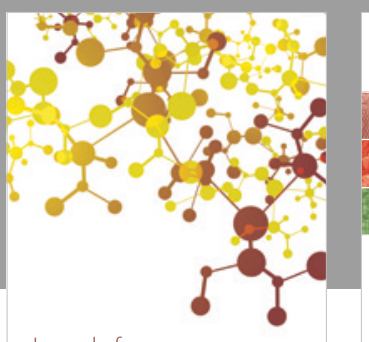

Journal of

Applied Chemistry
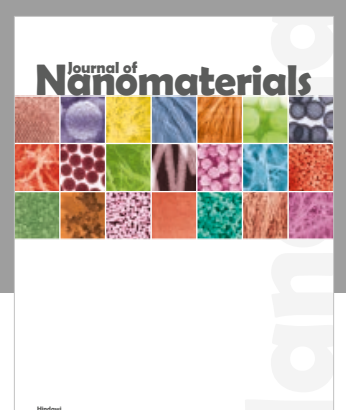

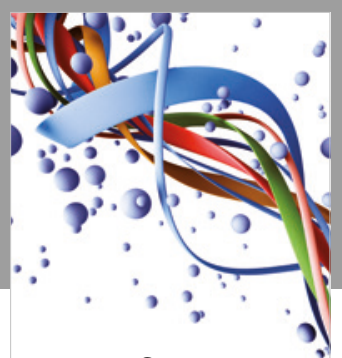

Scientifica

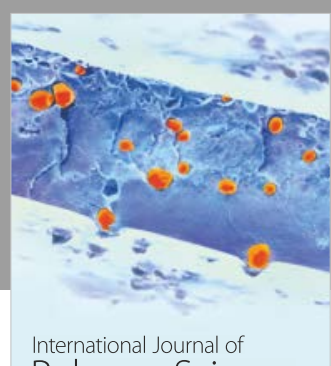

Polymer Science

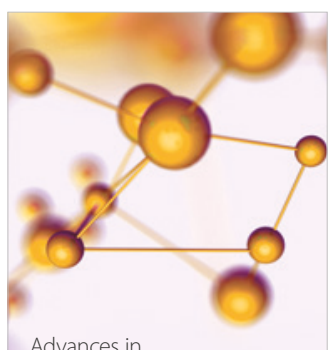

Physical Chemistry
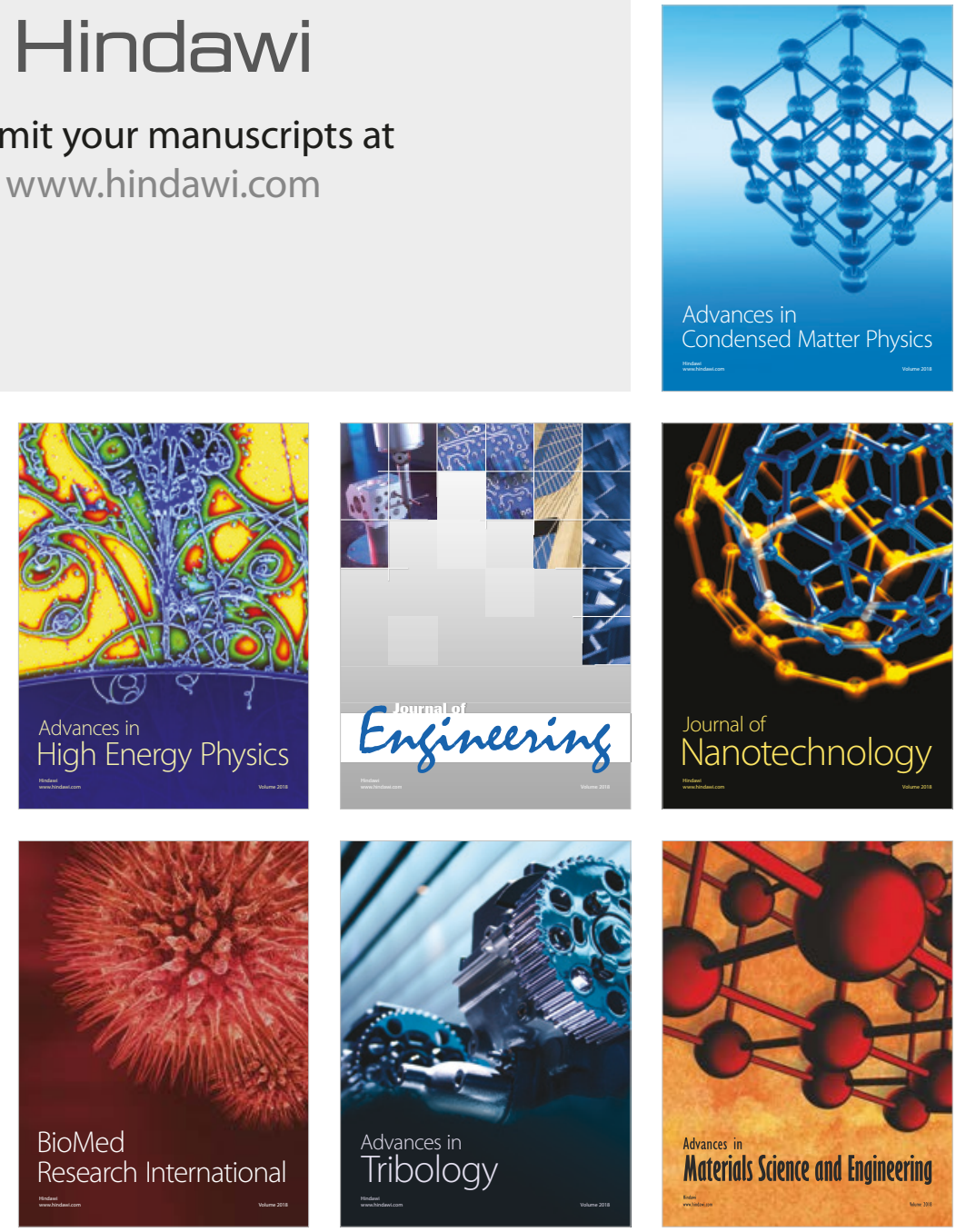